\title{
Naturopathic doctors gaining new powers
}

Published at www.cmaj.ca on Nov.13

$\mathrm{N}$ aturopathic doctors in Ontario and British Columbia are celebrating legislative gains that will allow them to prescribe drugs as well as natural products, and naturopaths in Manitoba and Alberta may soon be joining the party.

In Ontario, the provincial Standing Committee on Social Policy voted in October to approve Bill 179, which will amend the Naturopathy Act to allow qualified naturopaths to dispense, compound or sell drugs listed in accompanying regulations. Although the bill requires third reading and passage by the legislature, the Ontario Ministry of Health and Long-Term Care supports it and, given the Liberal majority, it is expected to pass.

The regulations that will determine which drugs naturopaths will be allowed to prescribe must still be hammered out - a process that could take up to three years. Although naturopathic doctors in Ontario believe they will eventually be able to prescribe basic primary care drugs and crash-cart medications, as in British Columbia, they also expect some lobbying against that power from organizations representing medical doctors.

"We feel very positive about the changes, the new regulations in British Columbia and what's being proposed in Ontario," says Shawn O'Reilly, executive director and director of government relations for the Canadian Association of Naturopathic Doctors. "What we're seeing is that shared scope of practice legislation is being tabled and approved across the country, and naturopathic doctors are being included in that legislation."

The changes are in the best interests of patients and will foster comanagement with medical doctors and others, she adds.

Not everyone appears warm to the notion of expanding naturopath prescribing rights beyond natural health products, though.

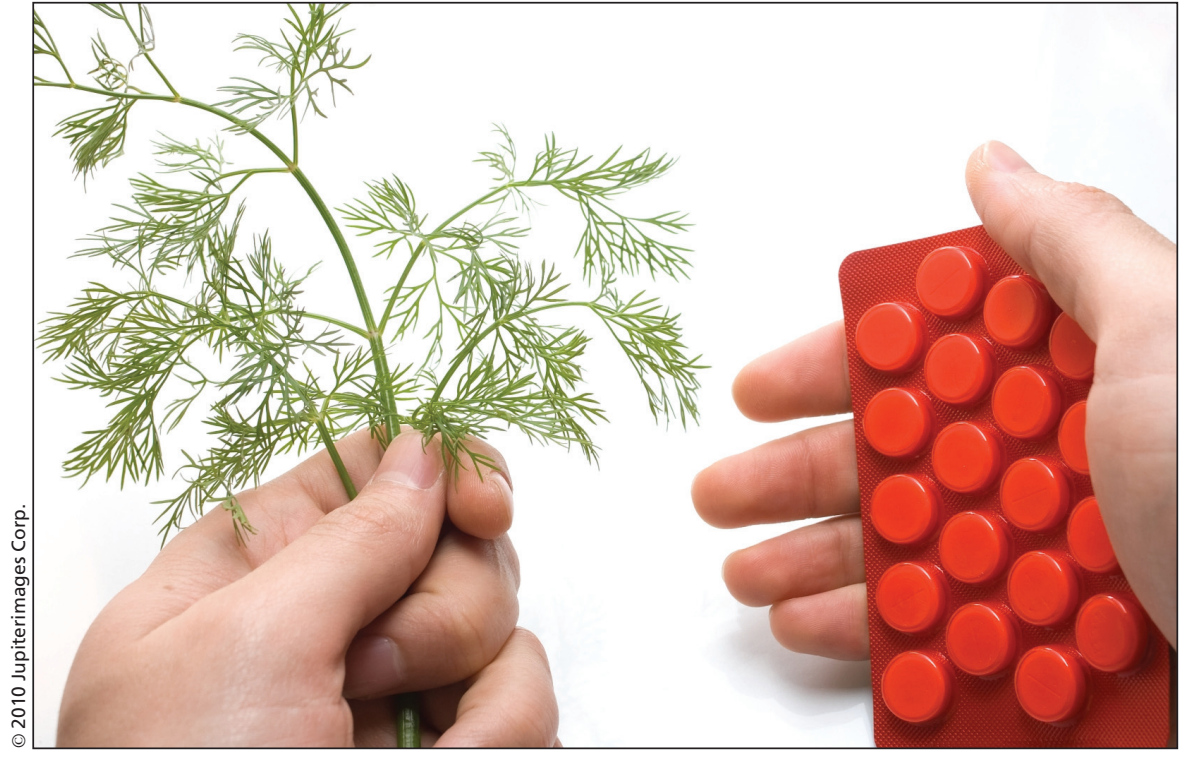

Will that be an herb? Or a drug? That prescriptive option will soon be available to many naturopathic doctors in Canada.

"The intent is just to allow them to do what they are already doing with the natural health products," says David Jensen, a spokesman for the Ontario Ministry of Health and Long-Term Care. Whether pharmaceuticals are added to the list of products naturopaths will be permitted to prescribe, compound and dispense "will need to be seen as it is spelled out in the regulations," he says.

In a statement, Dr. Suzanne Strasberg, president of the Ontario Medical Association, raised concerns about the proposed expansion of the scope of practice for naturopaths. "We believe that the use of pharmaceuticals or synthetic drugs is completely outside naturopathy's educational framework and scope of practice," she stated.

In British Columbia, the government last April passed legislation allowing naturopathic practitioners to prescribe Schedule I medications, which include basic primary care drugs such as antibiotics. In addition, qualified naturopaths will be able to prescribe hormones, botanicals, high-dose vitamins, amino acids and other natural substances they have traditionally used in their prac- tices, but which are increasingly coming under federal control and scheduling limitations. In many provinces such as $\mathrm{BC}$, only medical doctors, dentists and veterinarians could previously prescribe substances such as digitalis and other botanicals and hormones that naturopaths normally used.

Under BC's legislation and accompanying regulations, naturopaths will not prescribe certain restricted classes of medications, such as antipsychotics and chemotherapy drugs. The regulatory board that governs naturopathic doctors is now finalizing the standards and list of substances that naturopaths will be allowed to prescribe.

But they will first have to meet educational requirements and pass a qualifying examination, says Christoff Kind, president of the British Columbia Naturopathic Association. "The whole thing really is just based on providing for a shared scope of practice model here in BC, which I think is coming across the country," he says. "Professions that have the training should be allowed to practise to their level of education and expertise." 
The changes will mean that if a naturopath has a patient with acute pneumonia, for example, he will be able to prescribe an appropriate antibiotic instead of sending the patient to their family doctor, Kind says. "It will allow for more streamlined health care."

Meanwhile, Manitoba has just approved umbrella legislation regulating health care professions that is similar to that of BC. Naturopaths are expected to be included "as part of the second wave moved under that legislation," O'Reilly says. Alberta has done the same and regulations have been drafted there but not yet finalized.

In the United States, 11 of 16 jurisdictions that regulate naturopathic medicine have awarded naturopathic doctors prescribing authority. Although the pharmaceutical formulary varies in different states, it is extremely broad in Hawaii,
California and Washington. In Arizona and Oregon, naturopaths are allowed to prescribe most pharmaceuticals except some therapeutics and narcotics. In Utah, they may prescribe and dispense all noncontrolled drugs, while in Maine, they must first complete a one-year collaborative relationship with a medical doctor. — Laura Eggertson, Ottawa, Ont.

DOI:10.1503/cmaj.109-3112 